\title{
MILITARY INTERVENTION AFTER THE COLD WAR: THE EVOLUTION OF THEORY AND PRACTICE
}

\section{Andrea Kathryn Talentino}

Ohio: Ohio University Press, 2005

364 pages

Illustrated

ISBN 9780896802452

R368, 06

The 1992 United States-led international military operation into Somalia was a multilateral effort persuaded by and under the aegis of the United Nations (UN) to thwart a humanitarian crisis as a result of political cataclysm, civil unrest and natural disaster. The Unified Task Force (UNITAF) was mandated to create an environment conducive for the distribution of emergency aid against earlier attempts, which were derailed by warlords and the marauding gangs. The achievements on the humanitarian objectives were ephemeral because when the mission ended in 1993, an operation to make possible the political imperatives commenced, but all these efforts ended in violence. The ensuing withdrawal of its forces by the United States prompted the demise of UN operations and eventually the intervention was concluded with the political impasse unresolved.

Given the above backdrop, the introductory chapter of the publication focuses on how the fundamental changes in the understanding of security, governance, human rights and the gist of sovereignty have taken root since the demise of the Cold War. The author attests to the fact that the development of intervention has been an incessant process of trials and miscalculations. Notwithstanding the fact that the outcomes of interventions do not yet match the ideals, intervention as well as post-conflict reconstruction became prominent features in the international system. How that came about and its significance for the future of state activity becomes the subject of the book. The relentless evolutionary process directing contemporary intervention, has been a result of a myriad of unceremonious changes. Among these changes are those of globalisation, technology and liberal ideas which were brought about by innovation and diffusion. 
To give essence to and bolster the argument of two emerging trends in the international system, Talentino presents these trends as follows: the first has to do with more practical inclinations which culminated in the transformation of intervention from a product of power politics to that of conflict resolution, and the second relates to more theoretical underpinnings which led to the conceptual redefinition of security, sovereignty and the emergent human right issues. In the third chapter, Talentino suggests that the first litmus test for post-Cold War interventions and the ensuing evolution were set in Somalia in 1992. This was followed by the intervention in Haiti in 1994 that, amidst lingering criticism surrounding the Somalian ignominy, presented a degree of optimism with regard to intervention. The intervention in Bosnia in 1992 spanned the critical era in which intervention and security began to change with peace-building and nation-building as the fundamentals of intervention mandates. In this sense, intervention became synonymous with constructive means of resolution and reconstruction as opposed to occupation through coercive means.

The distinction between a diversity of intervention efforts such as Somalia, Haiti, Bosnia, Sierra Leone and Kosovo by means of different chapters, epitomises a comparative approach to depict the global changes and the emergent trends on security issues. It is, however, not clear whether this book attempts at prescribing intervention within this new security landscape. If post-conflict reconstruction and nation-building form the foundation of any intervention, given the "successes" in Bosnia, the Americans should have been out of Iraq sooner than anticipated. On the other hand, the failures in Somalia and other foiled interventions should have prompted such interventions to be revisited.

The chapter on intervention in Somalia as a case study elucidates the failures of the traditional methods of intervention through the use of force only, with humanitarian issues the primary concern. The chapter on Haiti presents a rather sanguine view of intervention with its rationalisation stemming from principles rather than people as the Haitian intervention took place to re-establish democracy. Bosnia on the other hand is symbolic of the post-Cold War changes in the international system. Even though humanitarian issues played a role in the intervention, self-interest by states can also be found given that some had to deal with refugee problems; thus the response and credibility of the North Atlantic Treaty Organisation (NATO) to stabilise Europe. The international intervention in Sierra Leone exhibits the relevance of contemporary norms on the partnership between a regional entity and an international organisation like the UN. The chapter on Kosovo, in turn, marked the advent of yet another change in intervention; that of a 
regional organisation waging war with a state and in this instance, NATO battled it out with Serbia.

Albeit a comparative case study approach on the evolution of intervention, this book focuses exclusively on how such an evolution helped shape intervention. A look at Africa in general, and Somalia and Sierra Leone in particular, helps explain the complexities that lie in understanding the roots of conflict as an impediment to conflict resolution efforts and intervention. This book serves as a constant reminder to the powers in being within the military establishment and their civilian counterparts on how intervention has evolved to the extent that traditional methods are rendered somewhat obsolete. Military Intervention After The Cold War: The Evolution of Theory And Practice is a remarkable reader for humanitarians, historians, strategists and security studies scholars alike. The publication informs scholars and practitioners about the shifting nature of intervention as a result of the new security landscape, globalisation and the diffusion of liberal ideas after the Cold War.

Capt Godfrey Ramuhala, Department of Military Strategy, Faculty of Military Science, Stellenbosch University 